\title{
La Honra Villana en el Teatro de Lope de Vega
}

\section{Por Washington Delgado}

Dice Allan Lewis, en su excelente libro: "El Teatro contemporáneo", que "el teatro del mundo occidental está demasiado alejado de los intereses y troblemas de las clases trabajadoras, a pesar de que desde mediados del siglo XIX los obreros no solamente se han organizado en numerosos y poderosos sindicatos, sino que en muchos países, como Inglaterra y los Estados Unidos constituyen ahora la mayoría de la población". Dice luego que "hoy dominan los personajes de la clase media", y "se supone que todas las personas son iguales, que su naturaleza humana es la misma, que aun los problemas sociales pueden generalizarse y que la clase medió es-típica y la más-interesante". Explica, el mismo Lewis que tal preponderancia de la burguesía en la escera teatral es recienie.e Anfesilellibsen nolhabía drama burgués. Raros y extraños precedentes son por ejemplo, "El Mercader de Londres" de George Lillo o "La Mandrágora", aunque esta última es una comedia, "género teatral en el que pueden aparecer artesanos - comercianies" para provocar risa y ser ridiculizados; mientras que la tragedia, antes del siglo XIX, está reservada a reyes y príncipes, caballeros y nobles. Por estas razones es causa de singular asombro una obra como "Fuenteovejuna", "en la cual - señala Lewis - el calor y la solidaridad de un pueblo permanecen íntegros ante la tiranía feudal"; aunque luego añade que Lope no volvió a tratar este tema, como si "el monstruo de la naturaleza, dice, hubiese conseguido abarcar en un solo intento todo el contenido del mundo en que vivió". En esta conferencia trataré, de un modo ciertamente muy imperfecto, de indagar como pudo escribir Lope una obra no sólo de tal calidad literaria que bastaría paro inmortalizarlo sino de tan adelantado espíritu revolucionario. 
Al estudiar una obra literaria suele el crítico empezar por el análisis de la personalidad del autor. Tarea llena de sorpresas, por decir lo menos, en el caso de Lope. Personalidad toda acción y sin resquicios, la suya, casi no se comprende cómo alcanzó a caber en el espacio de una vida humana. Cuenta Alfonso Reyes que "el anciano Goethe, emulado un día de noble envidia y refiriéndose a sus aficciones mineralógicas, decía más o menos: "¡Ojalá hubiera yo seguido el ejemplo de Lope de Vega, y me hubiera consagrado del todo a las juyas de la poesía, en vez de perder tanto tiempo en juntar piedras". Pero Goethe se olvidaba -agrega Alfonso Reyes- de que Lope no sólo se consagró a juntar las joyas de la poesía, sino que se revolvió constantemente en el fango de las pasiones. Se ha dicho ya que, al revés de Flaubert -otro ejemplo típico - en la disyuntiva de la vida y la obra, Lope siempre optó por la vida. Y con todo, la obra es inconmensurable superior en el caso. Aún suponiendo que no hubiera hecho más que escribir, resulta Lope un verdadero portento: mucho más si se considera que su existencia fue un torbellino de aventuras. Sus contemporáneos en parte por eso y en parte por la calidad poética, que es otra maravilla más dentro de la cantidad de su obra, le llamaron "el monstruo de la naturaleza". El autor de la República literaria dice de él que era "tan fecundo que la elección se confundió en su fertilidad; y la naturaleza, enamorada de su misma abundoncia, despreciól las sequedades y estrecheces del arte".

Esta cita, algo larga, del grande y llorado maestro mejicano me exime de mayores comentarios. Bastante se ha escrito ya acerca de Lope, y en rasgos generales todos conocen los azares de su existencia desde sus poéticas precocidades infantiles hasta sus desengaños últimos, desde sus insolentes amores con Elena de Osorio hasta su trágica novela con Marta de Nevares. Inútil sería además no sólo alargar el relato biográfico, sino también intentar sutiles inquisiciones psicológicas. La vida de Lope es tumultuosa y arrebatada, pero clara y abierta; no posee túneles ni corredores secretos; está libre de complicaciones o, como dicen ahora, de complejos. Como en el poema de Pedro Salinas, podríamos por buscarle la puerta del alma sin entrar jamás en ella, porque su alma, de pura que es, no tiene puertas. Hay un verso del propio Lope que puede pasar por divisa de su existencia: 
"No te detengas a pensar que vives"

Pero tengamos culdado, la falia de complicaciones no signifiea carencia de vida inlerior en Love; ni esto verso, tomerio como diviaa suya, indica ausencia de pensamiento; indica, en todo caso, que tanto la vida como el pensamiento son veloces indetenibles. Otros versos suyos aclararán tal vez la figura:

\section{"Dando voy pasos perdidos por tierra que toda es aire: que sigo mi pensamiento y no es posible alcanzarle"}

Lope, efeclivamente, no pudo ni quiso alcanzar su propio pensamiento. De haberlo hecho tal vez su historia no lendría el aire de placidez y dicha gue, a pesar de los desengaños finales, liene para nosotros. Pero ya atcanzaremos su raudo pensumienio.

Existencia libre de complicaciones ocullas, pero en la cual aparecen, aquí y allá, vorias contradicciones explícitas. Contradicción hay por ejemplo, af menos para la morosa mentalidad de nuestro siglo, entre da extensión de su obra y la alla calidad poética de la misma. Contradicción entre su profesión eciesiástica y su desordenada vida, entre su religiosidad espiritual y su vital sensualidad. Pépoi hạy ung goplyadicaién aque quiero resaltar ahora porque en ella, esta acaso una de las claves de su personalidad y de su obrd, esta coffradiccion entre plebeyos y nobleza. Lope, aunque de origen plebeyo, ambiciona por momentos la nobleza de sangre como la vez en que le dio por usar el escudo de los Carpio con sus diecinueve torres, uso que le costó el famoso soneto de Góngora:

\footnotetext{
"Por tu vida Lopillo que me borres las diecinueve torres de tu escudo porque, aunque todas son de viento, dudo que tengas viento para tantas torres".
}

Pero en otras oportunidades Lope nos habla de su "humilde sangre" y "la' humilde casa de sus padres". Y, como señala Vossler, no se atrevió nunca a anleponer el don a su nombre "aunque con un poco de habilidad hubiera sido cosa fácili pues los estudiosos, los letrados pasaban como una especie de aristocracia". 
Dice también Vossler: "Lope no quería que se le contara entre la clase media burguesa, ni entre el pueblo bajo, ni más ni menos que todos los españoles de su tiempo que se tenían en algo, sabían leer y escribir e incluso habían aprendido latín. A la nobleza, en sentido estricio - continúa Vossler- tampoco pertenecía". Lope en definitiva no es plebeyo ni noble; alguna vez se precia de la humildad de su casa pero siempre aspira a la nobleza y es en esto igual a todos los españoles de su condición y su tiempo. Aqquí está la explicación de su conducta: las fluctuaciones de Lope entre plebeyez y nobleza no constituyen una singularidad psicológica, tienen, en todo caso, un alcance social. El mismo Vossler dice: "Lo irregular e inconsiante de su conducta vitai proviene, en gran parte, de la contradictoria y dudosa naturaleza de su posición social, que en realiáad no era ki posición; y muchas cosas que uno se siente inclinado a achacar a la inquietud de su temperamento y a explicar psicológicamente, son, en verdad, de oriģen sociológico, a están sociológicamente condicionadas"

La contradicción esencial de la vida de Lope -plebeyez y nobleza- y muchas de sus otras contradicciones se iluminan a la luz del ambiente en que vivió. Si nos reducimos a la esfera literaria vemos una vasta cantidad de poesía, también contradictoria y tumultuosa. Es el exuberante barroco español donde confluyen dos escuelas diversas ${ }^{\circ} \mathrm{y}$ aún contrapuestas; el culteranismo y el conceptismo. Y vemos a Lope, como en la vida, como en el pensamiento, vemos a Lopeguchar entre dos aguads. La crítica ha señalado abundantemente las veces en que Lope es poéticamente libre, fácil, espontáneo y claro, y las veces que se hincha y se pica de hablar culto, difícil y erudito. En una de sus respuestas a Góngora dice, con un punto de falsedad que es su propósito "dejar oscuro el borrador y el verso claro". Se non é vero, é ben trovatto. Lo cierto es que a Lope le brota naturalmente la poesía y sin necesidad de podas, limas ni enmendaduras el verso le sale terso, grácil y gustoso. Pero alguna vez se echa a citar autoridades, mentar mitologías, y parlar latines; toda la crítica coincide en señalar la falsedad de esta manera lopesca; pero, y aquí relumbra la genialidad de Lope, se le abre de pronto la vena do la poesía y corre también por este cauce:

"Cuando el rocío del aurora hermosa

en copa de cristal teñida en grana

con brindis al jazmín bebió la rosa" 
Dice Azorín que "no tiene Góngora versos más peculiares, más suyos, más de su estro privativo".

Pero las contrapuestas escuelas literarias del barroco, las discordias civiles y aún militares entre escritores, la que Alfonso Reyes liamó "guerra literaria", no son, sino sombra y reflejo de una sociedad contradictoria. Ya hemos visto como Vossler cree que rnuchos de los conflictos psicológicos del monstruo de la naturaleza provienen de mús hondos confliclos sociales.

Vossler reduce éstos a uno solo: la equívoct posición social de Lope. Pero Lope es, así lo creo, el espejo de la sociedad de su tiempo, en su obra afloran aunque él no sepa, casi todos los problemas de la sociedad en que vivió. Lope no fue un escritor de tesis, ni tuvo doctrina política, y si alguna tuvo ésa fue la sana decirina conservadora, la única que podía tener un escritor popular en la imperial y católica España del siglo de oro. Pero ya examinaremos esto con más detalle, si el tiempo lo permile; lo cierto es que Lope refleja en su leatro la sociedad en la cual vive. $Y$ eso lo ha intuído la crítiea jaealista qunque no se ha atrevido $\alpha$ desarrollarlo. Así dice Vossler: La entrega, el abandono, la inmersión en su época, en su pueblo, y en el fondo elemental de su fe, alternando con magnílicos desahogos de su pasión y su idiosin. crasia, he aquí, creo yo, la ley de esta vida en apariencia tan irregular, y de esta labor creadora desbordante". De un modo más concreto, Alonso Zamora Vicente dice: "se tiene la sensación de que en Lope está todo, desde- la vialdeS hampa hasta la de la Universidad y Jtornobleza'in'Ĺle CuporarLope -continúa más adelante- ser el representante adecuado de la sociedad a que pertenecía... Lope, asimila el latido de su pueblo y lo muda en criatura de arte, dándole un ademán de extraordinaria belleza, pero sin puntos de vista nuevos o complicados sino fiel siempre a la multitud en que se encuenira y apoya". Es lástima que críticos tan esclarecidos y eminentes no se atrevieran a caminar todo el camino que intuyeron. Yo andaré unos pasos por él, pero es mi esperanza que otros investigadores, con más fuerzas y estudios que yo, completen el recorrido.

La vida de Lope, rica, variada y turbulenta, desprovista de recovecos interiores -."con razón Vega por lo siempre llana", dice Góngora- se nos aparece como un poético cristal que copia la vida de su tiempo. Para una explicación cabal de la obra de Lope es necesario introducirse en el tumulto de los siglos XVI y XVII. Epoca ésta de multiplicada variedad y de escabrosas complica- 
ciones que dificultan la orientación justa. Debo a la recomendación de mi amigo el Dr. Carlos Araníbar, catedrático de esta Facultad a quien agradezco públicamente, la lectura del libro de Fernand Braudel: "El Mediterráneo y el mundo mediterráneo en la época de Felipe II". Esta obra de Braudel me ha iluminado y orientado; casi todos los juicios históricos que enunciaré en seguida son desmañadas síntesis de este libro admirable.

Hay en la época de Lope gran copia de acontecimientos diversos, disímiles y contrarios unas veces, paralelos y coincidentes. otras. Ahí están el erasmismo, la reforma, la contrarreforma, el nacimiento del capitalismo y la industria, la expansión del comercio, el desarrollo de la ciencia, los descubrimientos marítimos, la conquista y colonización de tierras remotas, la pauperización de las masas, el alza de los precios, la consolidación de los grandes estados coloniales, las guerras religiosas, la rebeliones campesinas, la creación de grandes fortunas, la picaresca, el remozamiento de los ideales caballescos, la aparición de doctrinas políticas coherentes, la decadencia musulmana, el saqueo de Roma. Un laberinto en fin. Pero hay dos procesos que pueden servir, que nos servirán efectivamente de orientador hilo de Ariadna: uno es la evolución de la burguesía y su lucha con la nobleza; y el otro la grandeza y decadencia del Imperio Español. Empecemos por analizar este último proceso.

Lope vive en el apogeo del Imperio Español. Imperio asombroso por su vastedad $\mathrm{y}$ variedad, donde se aunan muchas lenguas, pueblos y religiones "europeas amen delos terfiforios ultramarinos y del cual Lope es un cumplido representante; la exuberancia de su teatro es paralela a la exuberancia imperial; sus temas son esencialmente nacionales; sus escenarios los del gran Imperio y así aparecen por igual en su teatro el "Nuevo mundo descubierto por Colón" o las Batuecas ese soterrado y misérrimo territorio español, llamado también Las Urdes, que arrastra hasta hoy su deplorable existencia como lo muestra "Tierra sin pan", el trágico film documental realizado por Luis Buñuel. Sí, Lope recorre toda la geografía del Imperio, afinca sus personajes en todos los parajes y recorre también todos los caminos de la historia española, ya sean legendarias hazañas de los reyes godos o ya recientísimas victorias nacionales; así, a las tres semanas de saberse en Madrid la victoria alcanzada por las huestes de Gonzalo de Córdova sobre los protestantes alemanes cerca de Fleurus, en Bélgica, a las tres semanas, repito, Lope tiene ya escrita su pieza: "La nueva 
vicloria de don Gonzcilo de Córdova". La velociciad de su pluma, acicateada por el sentimiento patriótico no cede terreno a la velocidad de la historia en el siglo XVII.

Pero cerca del Capitolio está la roca Tarpeya; múltiples indicios anunsicin ya la futura decadencia española: la prolifereción de la picaresca, el descalabro de la agriculiura, el desaprovechamiento de las victo:ias militares, el desastre de la Armada Invencible. Un espíritu agudo como el de Qusvedo pusde prever el amargo porvenir:

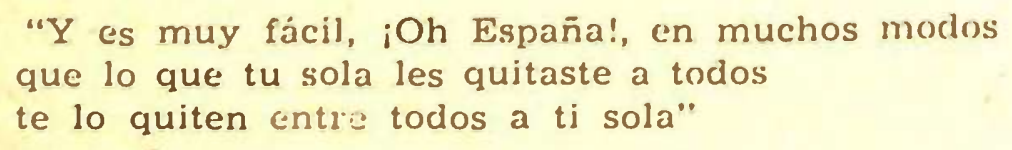

Lope, sin embargo, está ciego para tales vaticinios. Tal como el común de los españoles de su tiempo está enccindilado por la abundancia de las victorias y la anchura de los dominios; así en una comedia, La Juventud de San Isidro, representada en 1622, Lope puede decir:

$$
\begin{aligned}
& \text { "En este dichoso tiempo } \\
& \text { que Felipe Cuarto reina. } \\
& \text { y que reine muchos años, } \\
& \text { es justo que se prometa } \\
& \text { Biblimaeres bienes Españas } \\
& \text { "Jorge que en otros reinos se cuentan". }
\end{aligned}
$$

Si, Lope habla de Felipe Cuarto, el rey que dio en hacerse llamar el grande, y de quien Quevedo decía: "Nuestro rey es como los huecos, es más grande cuanto más tierra le quitan".

El otro proceso histórico, el de la evolución de la burguesía nos aclara el confuso panorama del siglo XVII y como corolario nos ilumina muchos pasajes de la obra de Lope. La burguesía irrumpe, en la llamada Edad Moderna, con singulares bríos: propicia los avances científicos, protege el desarrollo de las artes, promueve los descubrimientos y conquista de nuevas tierras, renueva el pensamiento filosófico, la moral, la religión. El capital muestra su poderío y las discordias por la sucesión de las casas reales son en el fondo guerras de banqueros; así, la elección de Carlos V como emperador de Alemania es para el ojo del observador avisado, uno de los grandes negocios de la casa Fúcar o Fugger. Un artículo reciente del Dr. Guillermo Lohmann Villena nos revela el papel 
preponderante que tuvieron los banqueros sevillanos... en el descubrimiento y conquista del Perú. El capital propicia todo, lo desarrolla todo, lo puede todo; su poder llega a tener resonancias místicas. El Cristóbal Colón de Lope de Vega dice fervorosamente:

Señor, dineros, que el dinero es todo:

es el maestro, el Norte, la derrota,

el camino, el ingenio, industria y fuerza,

el fundamento y el mejor amigo.

Pero a fines del siglo XVI, en España y en otros países mediterráneos, la burguesía ha perdido mucho de su empuje inicial y carece de fuerzas no ya para tomar el poder político sino aún para conservar su victoria sobre la clase social dominante, la nobleza. Se observa como gran parte de los capitales se retraen del mercado monetario y son invertidos en la compra de tierras. La pugna entre burguesía y nobleza adquiere un cariz favorable a esta última. Por una parte, la burguesía aspira a ennoblecerse y los reyes llenan sus arcas vendiendo hidalguías y marquesados y se multipliccin los ejemplos de matrimonios por interés entre nobles y villanos. Por otra parte la nobleza no quiere deshonrarse trabajando y por eso el Hidalgo de Toledo, en el Lazarillo de Tormes, puede con justicia elevarse a la categoría de arquetipo de la nobleza. En el plano iideológico lonbarguesíat-los dice Braudeltraiciona sus ideales, renuncia a capturar el poder y se conforma con ingresar a las filas de la nobleza. En cambio esta aguza los suyos y si muchas veces acepta los matrimonios con gente villana, es porque se ha convencido de que en el futuro el poder estará en el dinero. "Creedme, quien está forrado de dinero- dice Bandello- siempre y cuando esté bien forrado, es noble; sólo la pobreza es plebeya".

Los nobles además se defienden de las infiltraciones plebeyas, con diversas medidas: el número de familias grandes de España por ejemplo se limita a veinte. Por otra parte, es necesario señalar que en España y en Italia los productos agrícolas no se vieron afectados por el alza de precios que trajo consigo la expansión del capital; por ese motivo la nobleza, cuya riqueza reside en la posesión de la tierra, conserva su poderío. Por ese motivo también muchos burgueses procuran adquirir tierras que además de producirles pingües beneficios los liberan de las incertidumbres del mercado monetario. 
Pero si la burguesía traiciona sus ideales, no traiciona sus ganancias. En la economía no sucede lo que en la ideologia; la burguesía quiere ennoblecerse porque ser noble es un buen negocio. Los nobles están liberados de algunos impuestos, gozan de varias franquicias. La nobleza no es solamente un título, es también una renta. Y la burguesía al procurar ennoblecerse se muestra rendidamente fiel a su más caro amor: el dinero.

Estas líneas de fuerza del panorama social del siglo XVII aparecen claramente -ahora que las conocemos-- en el teatro de Lope. Así por ejemplo el matrimonio entre gentes villanas y nobles. En varias comedias aparece este motivo. Tomaré al azar una de ellas, la dilogía: "Los Tellos de Meneses" y "Valor, fortuna y lealtad". En esta obra Ordoño I rey de León, para asegurar la paz, quiere casar a su hija, la infanta doña Elvira, con Tarfe rey moro de Valencia; pero ella, repugnando el matrimonio con un infiel huye de la corte y se refugia en casa de unos labradores, los Meneses. Después de varias peripecias Tello de Meneses la requiere de amores y ella enamorada de las buenas prendas morales del labrador lo acepta y se casa con él. En la segunda parte, Alfonso, heredero de la corona de León se obstina en anular el matrimonio de su hermana y Tello de Meneses; al final Tello será armado caballero y todos vivirán contentos y felices. El triunfo del amor es una institución literaria típicamente burguesd. Elbamoras] disfraz de otros negocios menos poéticos. Es característico que en el teatro de Lope siempre que hay matrimonios entre villanos yn hobles" los villanos posean abundantes dineros; así sucede en la obra comentada; así también, en "El villano en su rincón". Lope de Vega es el feliz iniciador de uno de los temas favoritos de la gran novela burguesa del siglo XIX: el matrimonio por interés.

Además del motivo del amor igualador, hay otra característica, esta vez formal, y no temática, que se explica claramente a la luz de los conflictos sociales del tiempo en que Lope vivió. Esta característica es la abundancia de equívocos y disfraces en las comedias lopescas. "El infinito disfrazarse - dice Vosslerde los personajes femeninos con traje masculino, de los señores con vestidos de ladrones y obreros, representando papeles de danzantes, estudiantes, físicos y mendigos, ladrones, molineros, pastores, mercaderes, toreros, bufones, idiotas, mudos, moros, hechiceros fantasmas y monstruos, todo este ir y venir de los personajes de uno en otro plano vital y de una máscara en otra, es algo 
que no quiere ya ponerse de acuerdo con nuestra comprensión". Y más adelante dice todavía: "Deslindar bromas y veras, razón y desvarío en estas obras, sería una interminable y pedante faena". Para el insigne crítico idealista la abundancia de disfraces en el teatro de Lope es incomprensible y, en todo caso, el deslinde de la realidad es tarea pedante e interminable. Pero la facilidad de los personajes lopescos para vestirse y desvestirse con diversos y múltiples ropajes apunta a un ideal burgués en la época de su lucha contra la nobleza feudal. El feudalismo es un sistema de estamentos rígidos de modo que era imposible, o poco menos, pasar de una clase a otra; la burguesía en cambio propugna una sociedad aparentemente más flexible pues su fin último es encaramarse al poder desplazando a la nobleza. La abundancia de disfraces es también la ilustración dramática de otro ideal burgués: la esenciá incambiable de la naturaleza humana. Este ideal completa el anterior; sirve para defender a la burguesía de las clases sociales inferiores que deseen aprovecharse también de la flexibilidad social.

Lope es pues un representante bastante fiel de la burguesía de su tiempo, pero no olvidemos que uno de los ideales de esa burguesía es llegar a ser aristocracia. Eso explica muchas peculiaridades del teatro lopesco. Explica, en el aspecto formal la persistencia de varias características del teatro medieval: la simultaneidad de escenarios, la multiplicidad de acciones, la duración ilimitada de la acción dramática. Explicá también su lenguaje, predominantemente octosilábicol y cenver saspecto del contenido explica la persistencia de dos motivos feudales: el motivo del honor y el motivo de la fidelidad al rey.

El motivo del honor, visto con los impíos e implacables ojos contemporáneos, parece ridículo y grosero. Los mismos escritores españoles de hoy lo desprecian. Unamuno se burla de este motivo en su novela ejemplar "Nada menos que todo un hombre" y Valle Inclán lleva al extremo la mofa cuando en el romance de ciego del "Esperpento de los Cuernos de don Friolera" cuenta la falsa historia del teniente engañado que se vengó matando a su mujer, al asistente y al gato. Pero la obra de Vaile Inclán es apenas la caricatura de un romance del jurado de Córdova Juan Rufo, publicado en 1596; en ese romance el marido engañado después de matar a la esposa adúltera y a su amante: 


\section{"Siguió la matanza fiera como lobo en el aprisco: mató ancianos escuderos, a los porteros ariscos, las dueñas y las doncellas, los pajes, grandes y chicos, a los mozos de caballos, y hasta los perros mismos aullaron pasando muerte, y gatos dieron maullidos; a una mona y papagayo no les valieron graznidos, ni los inquietos saltos a un atribulado simio. Esta confección de sangres hacen de la casa un río, en que el honor se restaura cobra fuerza y queda limpio.}

En este romance se basa la obra de Lope: "Los comendadores de Córdova" y el Fénix/de los ingenios no nos ahorra ni la matanza de la mona y el papagayo. Esa venganza extremada más que feroz es ridícula e irrisoria. Y es que el motivo del honor feudal estaba gastado ya en el propio siglo de Oro, y uno de los méritos de Lope es remozarlo al unirlo a los villanos. Pero eso lo veremos con la venia de Cronos, más adelante.

El motivo del honon era pues, ya un cadáver en el Siglo de Oro. Util solamente para buscones, estebanillos, rinconetes y pícaros de todá laya. Hay que ver el encarnizamiento de Ginés de Pasamonte en defender su apellido o la fría y apasionada entereza con que el Hidalgo de Toledo se muere de hambre por no deshonrarse trabajando. $Y$, sin embargo, en la edad media, la honra fue acicate de la reconquista y fundamento de la nacionalidad. Por eso la honra es uno de los motivos más altos de la literatura en España medieval. En el más grande poema épico español, el del Mío Cid, el motivo central, como revela en brillante análisis Pedro Salinas, es el motivo de la honra. Todo el poema es un perder y recuperar la honra. Al ser desterrado el Cid, le dice a Alvar Fáñez: "Albricias, Albar Fáñez, ca echados somos de tierra. Mas a gran ondra tornaremos a Castiella". $Y$ cuando Jimena se encuentra con el Cid en Valencia lo primero que hace es agradecerle el que la haya sacado de la deshonra. Los infantes de Carrión se casan con las hijas del Cid para crecer en honra. Posteriormente se vengan del Cid deshon- 
rándolo felonamente en la afrenta de Corpes. Pero el Cid recupera su honra y con las nuevas bodas de sus hijas "crece la honra de Mío Cid Campeador". Y por último la honra del Cid inunda el orbe, cuando en el romance final dice el Jugiar: "A todos alcanza ondra por el que en buena hora nación". Y. en el más grande poema lírico del medio evo español, las Coplas de Jorge Manrique, la honra tiene un alto lugar en las palabras que la muerte dirige al Maestre Don Rodrigo Manrique:

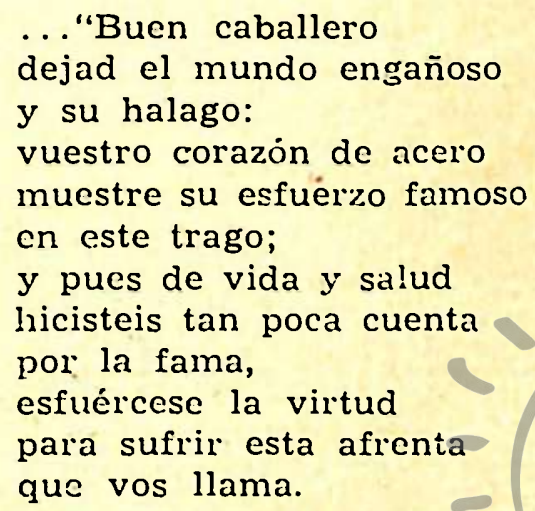

No se os haga tan amarga

la batalla temerosa

que esperáis.

pues otra vida más larga

de fama tan gloriosa acá dejáis.

Aunque esta vida de onor tampoco no es eternal ni verdadera, más con todo es muy mejor que lo otra temporal perescedera".

La vida del honor, en el pensamiento medieval, sólo es inferior a la vida de la gloria eterna.

Creo que estos ejemplos basian para demostrar la imporiancia y excelencia de la honracenlal vida medieval; así como el romance de Juan Rufo y el drama de Lope significan su decadencia posterior. Como dice Carlos Marx comentando una frase de Hegel: "los grandes hechos y personajes de la historia unjversal se producen dos veces: una vez como tragedia y otra vez como farsa".

Después de esta necesariamente breve y lamentablemente desordenada historia del motivo de la honra pasaré a precisar como Lope lo remoza insertándolo en la vida villana. Antes debo indicar que la honra villana no es invención lopesca; el poeta la tomó de la realidad. El rey en su lucha contra el poder feudal y la enemiga morisca se apoyó en los villanos y en pago de su adhesión los dotó de fueros y privilegios al tiempo que los protegía de las exacciones de los nobles. El rey, pues, dignificó y honró a los villanos. De aquí procede el sentimiento de la honra villana y la fidelidad al rey. 
El motivo de la honra villana tiene, en el teatro de Lope, tres aspectos: la pugna entre villanos y nobles, el elogio de la vida villana y la conciencia colectiva villana.

En el primer aspecto, el de la pugna entre villanos y nobles, no entraré en mayores perfiles históricos. Todos saben que al finalizar la llamada Edad Media hay una guerra continua entre el rey y los villanos por una parte y los señores feudales por otra. Entre las muchas obras de Lope que ilustran esta pugna, he escogido dos: "El mejor alcalde, el rey" y "Peribáñez y el comendador de Ocaña".

En la primera el campesino Sancho de Roelas quiere casar con Elvira hija de un rico aparcero y le pide licencia al señor feudal de la región, don Tello de Neira, solterón empedernicio. Pero el señor feudal al ver a la novia se enamora violentamente de ella, aplaza la ceremonia nupcial y luego la rapta. El pobre Sancho acude a quejarse donde el rey Alfonso VII y obtiene una orden escrita que intima a don Tello restituir la novia a su prometido. El señor rehusa cumplir la orden y aumentando su deseo viola a su prometida. Sancho vuelve al rey y le suplica envís un alcalde que haga justicia. Pero Alfonso VII decide ir el mismo; de incógnito se hace recibir por don Tello, escucha do labios de Elvira la historia del crimen, y luego de darse a conocer, sentencia que el señor feudal se case con Elvira y después de nombrarle heredera de una parte de sus bienes, sea ejeculado.

A través de estatrapidísima sintesis Sdel argumento vemos como la obra cuyg acción sel sitúg en el siglo XII, ilustra la pugna entre villanos y nobles, en un ambiente típicamente feudal: el villano se venga del señor sólo con la ayuda del rey.

En la segunda de las obras escogidas como ejemplo, el labrador Peribáñez mata al Comendador de la villa de Ocaña que preiende ultrajar a su mujer Casilda. Perseguido por la justicia y puesta a precio su cabeza, se entrega para que su mujer pueda cobrar el premio, pero el rey, después de oír la narración de lo ocurrido, le perdona y confirma en su cargo de capitán de los hombres de Ocaña. En esta obra, cuya acción se sitúa a fines del siglo XIV, el labrador se venga solo, sin protección ni ayuda de rey alguno. La personalidad del villano ha cobrado mayor importancia, incluso literariamente, pues Peribáñez, como personaje dramático, es rnuy superior a Sancho de Roelas: Yo quiero destacar aquí, sobre todo, el ensanchamiento moral del alma villana. En "El mejor alçalde, el rey" el valor moral de los vị- 
llanos es pasivo, resistente, no más; así Elvira, cuando Don Tello, antes de forzarla intenta seducirla, dice:

Soy mujer y tengo amor:

nada has de alcanzar de mí.

Y Sancho de Roelas, cuando Don Tello quiere matarlo, dice:

Yo soy contento

de morir y no vivir, aunque es $\tan$ fuerte el morir.

Valor estoico e inactivo. En cambio, el valor moral de Peribáñez no sólo es activo sino activísimo. Y no tanto cuando castiga las asechanzas a su honor con propia mano, sino cuando entrega su cabeza para beneficiar a. su esposa.

El segundo aspecto de la honra villanesca en el teatro de Lope es el elogio de la vida villana, o para decirlo con una frase clásica: el menosprecio de corte y alabanza de aldea. Este elogio o alabanza se presenta en dos formas: como efusión lírica en diversas comedias y también como central motivo dramático. Veamos algunos ejemplos líricos. En Fuenteovejuna, dice Laurencia, después ide comentar con sus amigas algunas hazañas amatorias del Comendador $\mathrm{y}$ sus gentes:

¡Pardiez!, más precio poner, Pascuala, de madrugada, un pedazo de lunada al fuego, para comer, con tanto zalacatón de una torta que yo amaso, y hurtar a mi madre un vaso del pegado cangilón, y más precio al mediodía ver la vaca entre las coles, haciendo mil caracoles con espumosa armonia; y concertar, si el camino me ha llegado a causar pena, casar una berenjena con otro tanto tocino; y después un pasatarde, mientras la cena se aliña de una cuerda de mi viña, que Dios de pedrisco guarde; y cenar un salpicón con su aceite y su pimienta, y irme a la cama contenta y al induzcas tentación rezalle mis devociones; que cuantas raposerias, con su amor y sus porfías, tienen estos bellacones; porque todo su cuidado, después de darnos disgusto, es anochecer con gusto y amanecer con enfado. 
Hay en estas cuartetas, apesar de la gracia del ritmo, un sabor acre, apasionado y rebelde, muy en consonancia con el carácter de Laurencia, la esquiva y valerosa villana que encabezará después la rebelión contra el Comendador. La actilud de Laurencia, rústica y sin pulimento, contrasta con la muello decadencia de los nobles que al abandonar sus feudos e insicrlarse en las Cortes Reales no solamente pierden su poderío económico y su fuerza militar, sino también sus virtudes morales. Vaya como contraste del recitado de Laurencia, la anécdota, acaso falsa pero verosímil, del cortesano monarca francés Luis XV. Se cuenta que una dama de la corte de Versalles consiguió, después de muchos esfuerzos, elevarse a la codiciada categoría de amante real, y que en el momento de la posesión amorosa sólo atinó a decir: "Señor, que honor para mi casa".

Veamos oiro ejemplo lírico de elogío de la vida villana. Durante las bodas de Peribáñez y Casilda, encontramos este diálogo, que es un hermoso ejemplo de idilio a la villana:

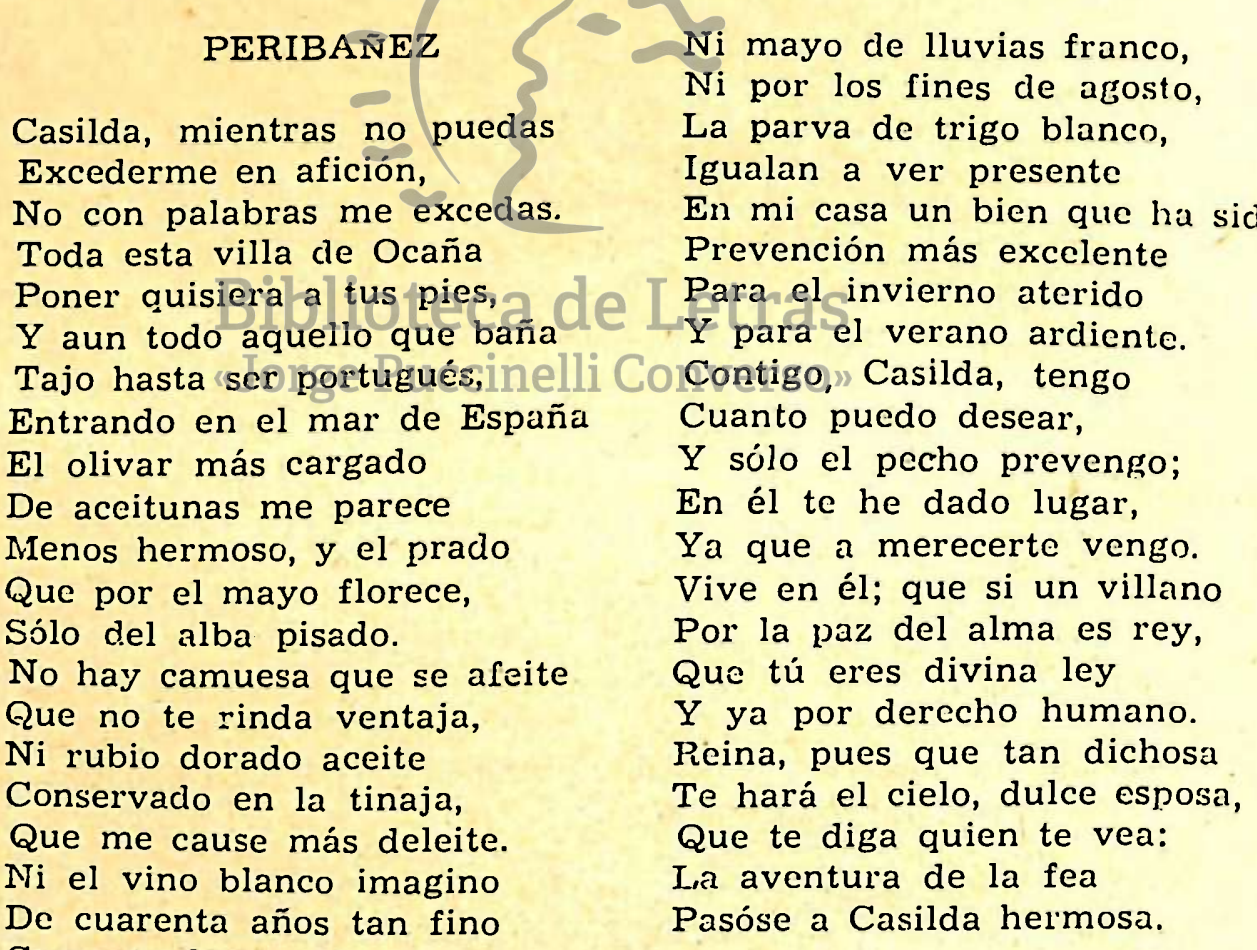

Como tu boca olorosa;

Que como al señor la rosa

Le huele al villano el vino.

Cepas que en diciembre arranco

$Y$ en octubre dulce mosto,

\section{CASILDA}

Pues yo ¿cómo te diré Lo menos que miro en tí, 
Qué lo más del alma fue?

Jamás en el baile oí

Son que me bullese el pic, Que tal placer me causase

Cuando el tamboril sonase,

Por más que el tamborilero

Chillese con el garguero

$Y$ con el palo tocase.

En mañana de San Juan

Nunca más placer me hicieron

La verbena y arrayán,

$\mathrm{Ni}$ los relinchos me dieron

Fl que tus voces me dan.

¿Cuál adufe bien templado

Cuál salterio te ha igualado?

¿Cuál pendón de procesión,

Con sus borlis y cordón
A tu sombrero chapado?

No hay pies con zapatos nuevos

Como agradan tus amores;

Eres entre mil mancebos

Hornazo en pascua de Flores

Con sus picos y sus huevos.

Pareces en verde prado

Toro bravo y rojo echado;

Pareces camisa nueva

Que entre jazmines se lleva

En Asafate dorado.

Pareces cirio pascual

Y mazapán de bautismo

Con capillo de cendal,

$\mathrm{Y}$ paréceste a ti mismo,

Porque no tienes igual.

Hay en este diálogo sus puntas de ironía; Lope mima aquí rasgos y motivos de pastoriles y cortesanos. Pero la verdad de la vida villana termina por imponérsele y la esiudiada sonrisa se trueca en poderosa poesía:

$\mathrm{Ni}$ el vino blanco imagino de cuarenta años tan fino como tu boca olorosa.

El lector de clásicos poemas corlesanos, donde las bocas femeninas son todas "corales y yerlas encuentral"en" la ruda comparación de Peribáñez el aroma incontaminado de un amor sincero.

Y para terminar con los ejemplos líricos, leeré el bello romance que Casilda pronuncia para rechazar los requirimientos amorosos del Comendador disfrazado en traje de labriego:

\section{CASILDA}

Labrador de lejanas tierras, Que has venido a nuesa villa, Convidado del agosto, ¿Quién te dió tanta malicia? Ponte tu tosca antiparra, Del hombro el gabán derriba, La hoz menuda en el cuello, Los dediles en la cinta. Madruga al salir del alba, Mira que te llama el día,
Ata las manadas secas Sin maltratar las espigas. Cuando salgan las estrellas A tu descanso camina, $Y$ no te metas en cosas De que algún mal se te siga. El Comendador de Ocaña Servirá dama de estima, No con sayuelo de grana $\mathrm{Ni}$ con saya de palmilla. Copete traerá rizado, Gorguera de holanda fina, 
No colia de pinos tosca

$\mathrm{Y}$ toca de argentería.

En coche o silla de seda

Los disantos irá a misa;

No vendrá en carro de estacas

De los campos a las viñas.

Dirále en cartas discretas

Requiebros a maravilla,

No labradores desdenes,

Envueltos en señorías.

Olerále a guantes de ámbar,

$A$ perfumes $y$ pastillas;

INo a tomillo ni cantueso,

Poleo y zarzas floridas.

$Y$ cuando el Comendador

Me amase como a su vida

$Y$ se diesen virtud $y$ honra

Por amorosas mentiras,

Mas quiero yo a Peribáñez

Con su capa la pardilla

Que al Comendador de Ocaña
Con la suya guarnecida.

Mas precio verle venir.

En su yegua la tordilla,

La barba llena de escarcha

$Y$ de nieve la camisa,

La ballesta atravesada,

$Y$ del arzón de la silla

Dos perdices o conejos,

$Y$ el podenco de trailla,

Que ver al Comendador

Con gorra de seda rica,

$Y$ cubiertos de diamantes

Los brahones y capilla;

Que más devoción me causá

La cruz de piedra en la ermita

Que la roja de Santiago

En su bordada ropilla.

Vete, pues, el segador,

Mala fuese la tu dicha;

Que si Peribáñez viene,

No verás la luz des clía.

En estas palabras de Casilda ya no hay puntas ni atisbos de ironía lopesca, todas son pura poesía y tal calidad que sería difícil encontrarle parangón en toda la literatura amorosa castellana. En el romance de Casilda relumbra, con cegadora luz, el orgullo de sér villano.

Y ahora veamos como el elogio de la vida villena y el orgullo de ser villano no sólo se presta para bellas efusionos líricas sino que alcanza a ser motivo central de una comedia. He eszogido también dos obras para la ilustración de este tema: "El cuerdo en su casa" y "El villano en su rincón".

En la primera de las comedias nombradas, el protagonista. Mendo, hijo de un carbonero, y casado con la hija de un labrador vive modestamente aunque tiene bienes suficientes como para poder vivir con mayor rango y altura. Un abogado vecino suyo, Leonardo, quiere inducirlo a que cambie de estado y la eche de hidalgo y de caballero; pero Mendo le responde:

El que nació para humilde

mal puede ser caballero;

mi padre quiere morir,

Leonardo, como nació;

carbonero me engendró,

labrador quiero morir. 
Al final de la comedia Leonardo se enreda en sus propias ambiciones y Mendo le presta ayuda y consejo. Esta obra, tiene un acusado carácter medieval. Mendo se enorgullece de vivir humildemente pero ese orgullo es, principalmente, conformidad con el orden social establecido, sumisión a la rígida organización feudal.

En "El villano en su rincón" en cambio, el orgullo villa:io tiene un carácter progresista. El protagonista, Juan Labrador, rico campesino francés se precia y vanagloria de no haber visto nunca al reyi aunque está dispuesto a sacrificar por él todas sus riquezas no quiere verlo jamás. Y es tanto su orgullo villano que en la Iglesia donde yacerá su cadáver, ha hecho grabar el siguiente epitafio:

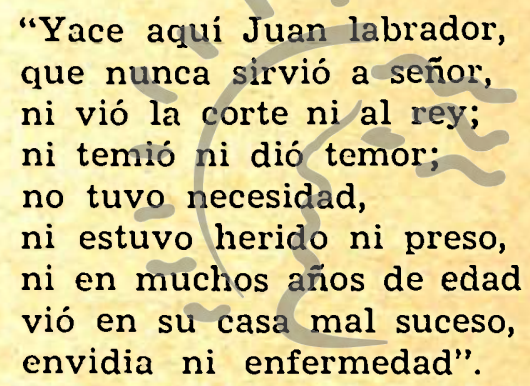

\section{Biblioteca de Letras}

El rey, casualmente',liega Galeer este epitafio y, al saber que está vivo, se pica por conocer al autor. Pero ante la imposibilidad de que el labrador lo busque tiene él, el rey, que buscar al labrador. Lo visita pues, de incógnito, y le conmueve profundamente su ideal de vida. Al final de la comedia, el rey llama a la corte a Juan Labrador y le da un alto cargo, nombra caballero a su hijo y dota a su hija y la casa con un cortesano. "Estó solución -dice Ferrarín- sería un mentis a las premisas, si en el lector no se albergase la certeza de que no es labrador quien necesita del rey, si no que es el rey quien necesita del campesino".

El mismo Lope parece haberse dado cuenta del espíritu progresista y casi revolucionario de ésta, su obra, al situar la acción no en España sino en una Francia irreal y de opereta. La aparente sumisión de Juan Labrador a la institución real está contradicha por multitudes de frases suyas, como por ejemplo esta: 
Reyes los que viven son

del trabajo de sus manos.

Pero es, sobre todo, sumamente reveladora la primera entrada de Juan Labrador en escena. Aparece riñendo a sus labradores de esta manera:

\author{
JUAN LABRADOR \\ Creo que os he de reñir \\ con las hoces en las manos. \\ FILETO \\ ¿Ya escopienzas a reñir? \\ Pero donaire has tenido, \\ pues cortesanos nos llamas, \\ pensando que nos infamas, \\ con ese honrado apellido. \\ JUAN LABRADOR \\ Fileto el nombre "Villano" \\ del que en la villa vivia, \\ se dijo, cual diria \\ de la "corte" el "cortesano" \\ Bib Elacortesano recibe tIaS \\ por afrentar aqueste nombre. \\ siendo villano aquel hombre \\ bueno, que en la villa vive. \\ Yo, pues nos llama villanos \\ el cortesano a nosotros, \\ también os llamo a vosotros \\ por afrenta "cortesanos".
}

No pudo llegar, no ha llegado, en toda la literatura castellana, a más alto punto el orgullo villano. La violencia del motivo central de esta obra es tanta que Lope se vio obligado a' temperaria poniendo en la mente de Juan Labrador, gran admiración y envidia por la vida cortesana. Es una concesión que Lope hace al orden social establecido y que le sirve además para bordar sabiamente la trama principal de la obra. Pero nada amengua la pugnacidad de la comedia. No hay sólo orgullo villanesco sino también burla de la corte y de la cortesanía, como en este diálogo de dos campesinos de la heredad de Juan Labrador. 


\begin{abstract}
BRUNO
Más dice: ¿sabrás tú ser cortesano?
\end{abstract}

FILETO

Pués ¿hay cosa más fácil?

\title{
BRUNO
}

¿De qué suerte?

FILETO

No sé si acierto, lo que pienso advierte/ cumpliendo extrañas, ceremonias,/ reverencias, los cuerpos espetados,/ mucha parola, murmurar donaires,/ risa falsa, no hacer por nadie nada,/ notable prometer, verdad ninguna,/ negar la edud y el beneficio hecho,/ deber... y otras cosas más sutiles/ que te diré después por el camino./

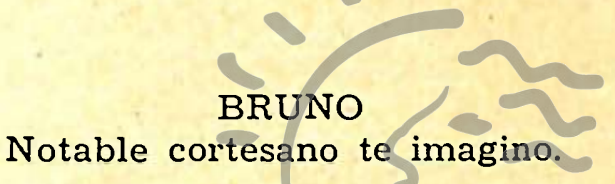

Burla acerada que disimula mal una queja y una censura enconadas. Veamos por último una certera saeta que alude, sin tapujos a un agudo problema de la época: la despoblación del campo:

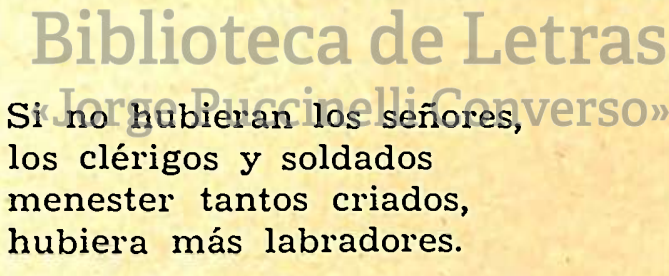

Esta satírica cuarteta es de un realismo profundo. Como dice Braudel: "La primacía de la tierra y la moda: todo conspira a crear una aristocracia ociosa y henchida de vanidad. Evolución que se traduce para los pobres, en cargas cađa vez más pesadas". No es necesario agregar nada. "El villano en su rincón", es, sin duda, una de las obras más realistas, más aguda y más valientes de la ingente producción lopesca.

Y llegamos al último aspecto de la honra villana en el teatro de Lope: el de la conciencia colectiva de la honra villana. No ha sido necesario escoger ilustraciones para el tema pues hay una sola, la más excelsa de todo el teatro del siglo de oro: "Fuente ovejuna". 
Inútil sería reseñar el argumento de esla obra, de sobra conocido. Inútil tambión referirse al suceso real que le dio origen. Pero quiero bien señalar, anie todo, que eso origen no puede referirse exclusivamente a un episodio singular y cmecdótico. "Fuente Ovejuna" no es la dramatización de un acio heroico pero aislado, sino el reflejo de una situación social. "La enorme revolución de los precios- dice Braudel- infla lambién los salarios, pero más de viento que de susiancia, pues su progresión va siempre a la zaga de la del costo de la vida. En España - ol único país en la que se han hecho investígaciones a cerca de éste -ol salario real no cesa de descender entro los años 1520 y 1600 y la caída es sumamente brusca de 1588 a 1600. Durante la segunda mitad del siglo XVI, la capacidad adquisitiva de un obrero urbano disminuye alrededor de una cuarta parte con relación a la primera mitad del siglo. "La historia-dice más adelanto- rara vez proyecta su luz sobre la vida de los pobres. Pero estos se las arreglan para obligar a los poderosos a fifarse en ellos, haciendd también de rechazo, que nos fijemos nosotros. Asonadas, motines, disturbios, revueltas, la alarmante multiplicación de los vagabundos y maleantes, los incesantes golpes de mano de los bandidos, todo este escándalo, aunque ahogado muchas veces, revela el pasmoso aumento de la miseria en las postrimerías del siglo XVI, llamado a crecer todavía más en el transcurso del siglo siguiente". Aquí termina la cita. Recordemos que-Fuenie Ovejuna fue escrita hacia 1618.

Quiero que resalte, en seguida, otro hecho importante: el valor moral y la heroicidad civil del pueblo de Fuente Ovejuna aparece no sólo en la acción sino también en la pasión. Este Pueblo se comporta valerosamente al derrocar al tirano, pero su valor se agiganta en los instantes de derrota y de sufrimiento y así al final la victoria es suya. El rey lo admite al terminar la obra:

$$
\begin{aligned}
& \text { Pues no puede averiguarse } \\
& \text { el suceso por escrito } \\
& \text { aunque fué grave el delito } \\
& \text { por fuerza ha de perdonarse. }
\end{aligned}
$$

El mensaje es claro, fuese cual fuese el pensamiento de Lope, cuando el pueblo se une de un modo inquebrantable no hay fuerza que lo derrote.

Huelgan más análisis literarios de "Fuente Ovejuna", pero quiero hacer notar un detalle que acentúa su carácter progresis- 
ta. Es un diálogo entre Barrildo y Leonelo; Barrildo es un labrador, vale decir un villano; Leonelo es un licenciado en Derecho al servicio del comendacior, heredero de los doctores de la escolástica medieval y espejo de los intelectuales vendidos a las tiranias.

\section{ACTO SEGUNDO. ESCENA II.}

Leonelo.- A fe que no ganéis la palmatoria, Porque ya está ocupado el mentidero.

Barrildo.Leonelo.Barrildo.Leonelo.¿Cómo os fué en Salamanca?

Un Bártulo seréis.

Es larga historia.

Es, como digo, cosa muy notoria.

In esta facultad lo que os reficro.

Barrildo.- Sin duda que venís buen estudiante.

Leonelo.- Saber he procurado lo importante.

Barrildo.- Después que vemos tanto libro impreso, No hay nadie que de sabio no presuma.

Leonelo.- Antes que ignoran más siento por eso, Por no reducir a breye suma; Porque la confusión, con el exceso, Los intentos resuelve en vana espuma; $\mathrm{Y}$ aquel que de leer tiene más uso, De ver letreros sólo está confuso.

No niego yo que de imprimir el arte Mil ingenios sacó de entre la jerga, $Y$ que parece quecen sagrada parte Sus obras guarda y contra el tiempo alberga, $\mathrm{Y}$ éste las distribuye yl las reparte. Débese esta invención a Gutemberga, Un famoso tudesco de Maguncia, En quien la fama su valor renuncia. Mas muchos que opinión tuvieron grave Por imprimir sus obras la perdieron; Muchos sus ignorancias imprimieron. Otros, en quien la baja envidia cabe, Sus locos desatinos escribieron $Y$ con nombre de aquel que aborrecían, Impresos por el mundo los envían.

Barrildo.- No soy desa opinión.

Leonelo.El ignorante Es justo que se vengue del letrado.

Barrildo.- Leonelo, la impresión es importante.

Leonelo.- Sin ella muchos siglos se han pasado, $Y$ no vemos que en éste se levante Un Jerónimo Santo, un Agustino.

Barrildo.- Dejadlo, y asentaos, que estáis mohino. 
Veamos en este pasaje que el sabio pedante desprecia el invento de la imprenta; $y$ en cambio es nolable el aprecio en que la liene el ignorante labrador. Son las clases oprimidas en ascenso - como es el caso de los villanos del siglo de oro-- quienes propician los avances de la tésnica y la ciencia. en cambio las clases opresoras en decadencía procuran frenar esos mismos avances. Curioso es aderrás el argumento del pedante Leonelo: "Sin ella ( que en este se levante un Jerónimo santo, un Agustino". Y es curioso el argumento porque parece del día. Los intelectuales de las clases opresoras siempre llevan una discusión de problemas sociales a un plano moral y procuran contener las ansias de perfeccionamiento de las clases desposeidas con el falaz argumento de que el progreso es ilusorio y que lo único real e importante es la moral, moral que, entre paréntesis tiene por norma primera, respetar a los opresores.

Después de esta vision de la honra villana en el teatro de Lope de Vega, que he comenzado a dibujar con la mayor precisión posible, quiero referirme al motivo del honor, en general y ya no solamente villano, en la obra lopesca. Espero que estas disposiciones finales sirven para redondear el panorama y me adelanto a pedir disculpas por la falta que muchas causan en el benevolente auditorio.

En primer términoes necesario subrayab un hecho conocido: a pesar de todos sus dramaśnsahioumarios; L Lope reprueba la venganza por motivo de honra; en su novela - y recordemos que el género narrativo se presta más que el dramático a las confesiones del escritor - en su novela "La más prudente venganza", Lope dice: "He sido de parecer siempre que no se lava bien la mancha de la honra del agraviado con la sangre del que le ofendió, porque lo que fue no puede dejar de ser, y es desatina creer que se quita, porque se mata al ofensor, la ofensa del ofendido".

En segundo término, hay veces en que Lope se burla de la venganza del honor agraviado. En su comedia "Las ferias de Madrid" un marido engañado quiere convencer a su suego, para que, como los padres romanos de la antigüedad, vengue la deshonra de su hija, matándola. Pero el suegro no se deja convencer y más bien mata a su yerno. Y dice después de haberlo matado:

"Más muera quien hoy deshonra hija, suegro, padre y madre. 


\begin{abstract}
Aqueste hecho es de padre que sabe de amor y honra.

Si yo mi hija mataba como adúltera y lasciva, dejaba deshonra viva que para siempre duraba;

el honor ha de vivir; es mujer y puede errar; $y$ yo padre y perdonar; y éste, mortal, y morir".
\end{abstract}

En tercer término y último, el honor suele ser en las comedias de Lope disfraz de problemas más profundos. Veamos por ejemplo el caso de "El mejor Alcalde, el rey", obra que escojo porque no hay que tener la molestia de echarse a buscar las fuentes de las anécdotas, pues el propio Lope, por boca de Sancho, nos da su fuente: "La Crónica General" y efectivamente en ella encontramos que un labrador gallego agraviado por un señor feudal fue a pedir juicio al rey Alfonso VII y que el rey le envió una carta al señor feudal no hizo caso de la carta y el labrador volvió a acudir al rey y el rey decidió ir personalmente a Galicia y fue efectivamente, de incógnito, y se descubrió ante el señor feudal y lo recriminó por su desobediencia a la orden real y lo castigó mundándolo ahorcar ante su puerta y reparó el agravio hecho al labrador. Esta anécdota de la Crónica General es cabalmente el argumento de la comedia de Lope. Pero el agravio, según la Crónica, no fue el rapto degningunainovia sino eque el señor feudal le había tomado por fuerza una heredad al labrador. Sin embargo, no vayamos a pensar que Lope disfrazó concientemente, con un deliberado propósito este conflicto. No. La verdad es que para Lope es inconcebible que la economía pueda ser fuente de motivos dramáticos, ninguna persona de su tiempo lo hubiera concebido tampoco. Tendremos que esperar mucho tiempo para que Ibsen se atreva, en "Casa de Muñecas" por ejemplo, a poner en escena un problema económico, y aun en esa obra ibseniana el problema económico, pese al ser el fundamento, se vela entre los vericuetos de la acción dramática. Lope tuvo, pues, que dramatizar la engorrosa y antiliteraria disputa de tierras y echó mano a lo que estaba más cerca: el motivo de la honra.

Aunque no siempre podamos encontrar un tan claro conflicto económico, podemos afirmar, como conclusión final, que en el motivo de la honra villana del teatro lopesco apuntan con un eficaz 
ropaje dramático, las aspiraciones revolucionarias de la burguesía de su tiempo.

Quiero, antes de terminar, que resalte un hecho incontrovertible: Lope no es de ningún modo un poeta revolucionario; como bien dice Vossler: "Lo particular y decisivo a la cbservación histórica en la conducta vital de Lope me parece residir en el hecho de que no haya actuado ni como reformador, ni como rebelde, ni como renovador; ní ilustrando, ni demoliendo. Antes bien, todas sus opiniones y convicciones más íntimas iban de tal modo acordes con la época y el pueblo a que pertenecía, que lo más llegó a tener enemigos personales $\mathrm{y}$ algunos envidiosos literarios, en su larga vida de creador, pero ningún vervadero adversario objelivo".

No, es un revolucionario Lope de Vega... Muy al contrario. se muestra siempre como un conservador, algo bohemio y aventurero, pero respetuoso siempre de las instituciones gubernamentciles de su época, sirviente fiel de la monarquía, admirador de la nobleza y devoto propagandista de la fe católica. No, Lope de Vega no es un poeta revolucionario. Le falta para serlo el ssntido de la hisioria, primera virtud que debe poseer un escritor inscrito en las filas de la revolución, cualquiera que ésta sea. Este granpoeta popular, lo diré glosando un párrato de Azorín, nos hace ver en su teatro las cinco partes del globo terráqueo, la antigüedad griega, la antigüedad romana, el cristianismo, el santoral, los héroes más aureolados del universo y las montañas y los ríos y los bosques y las ciudades. Sin embargo, este "lodopoderoso poeta del cielo y de Id therfa" notiene el sentido de" la historia; hemos visto ya cómo no alcanza a distinguir los signos de decadencia del Imperio Español, signos que sí pudo distinguir Quevedo. Lope aunque abunde poéticamente en anécdotas y episodios históricos, no alina a comprender el proceso de la historia; puede detener el instante, pero no contemplar el recorrido. Poeta popular, ignora los caminos históricos de su pueblo; cantor de España, desconoce la desasosegada ruta histórica de su patria. Y es en esto, como casi todos los ingenios de su tiempo. Dice Ricardo de Turia, en el "Apologético de la Comedia Española", que "la cólera española (y entiéndase por cólera temperamento o carácter) la cólera española está mejor con la pintura que con la historia... porque una labla o lienzo de una vez ofrece cuanto tiene y la Historia se entrega al entendimiento o memoria con más dificultad".

No, nada revolucionario hay en el alma de Lope. Y a pesar de que esto sea una verdad incontrovertible, desde los versos in- 
mortales de "Fuenieovejuna", el pueblo justiciero e igualador del Siglo de Oro extiende la mano a los pueblos igualadores y justicieros del siglo XX. Valga esta nueva contradicción Lopesca. $Y$ nadie se llame a escándalo porque la proclamemos, pues como dice Azorín: "El ver lo que el poeta no ve, es el signo magno de la verdadera poesía".

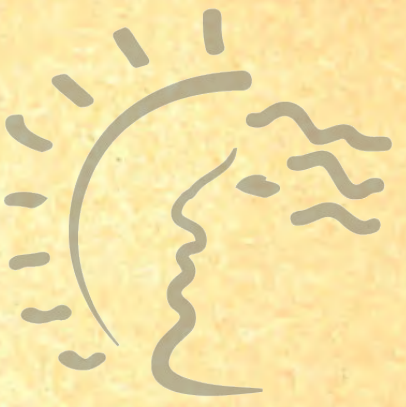

